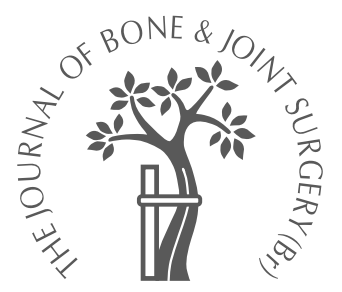

E. Tsiridis,

A. A. Narvani,

F. S. Haddad,

J. A. Timperley,

G. A. Gie

From the Royal

Devon and Exeter

Hospital, Exeter,

England

\title{
Impaction femoral allografting and cemented revision for periprosthetic femoral fractures
}

We reviewed retrospectively the outcome of the treatment by impaction grafting of periprosthetic femoral fractures around loose stems in 106 patients with Vancouver type-B2 and type-B3 fractures. Eighty-nine patients had a cemented revision with impaction grafting and a long or short stem. The remaining 17 had cemented revision without impaction grafting.

Fractures treated by impaction grafting and a long stem were more than five times likely to unite than those treated by impaction grafting and a short stem (odds ratio $=5.5,95 \%$ confidence interval (CI) 1.54 to $19.6 ; p=0.009$ ). Furthermore, those with impaction grafting and a long stem were significantly more likely to unite than those with a long stem without impaction grafting (odds ratio $=4.07,95 \% \mathrm{Cl} 1.10$ to $15.0 ; \mathrm{p}=0.035$ ).

There was also a trend towards a higher rate of union in those treated by impaction grafting than in those without (odds ratio $=2.69,95 \% \mathrm{Cl} 0.86$ to $8.45 ; \mathrm{p}=0.090$ ).

Impaction grafting is being increasingly widely used for the restoration of femoral bone stock. It can be successfully applied to periprosthetic femoral fractures but a long stem should be used to bypass the distal fracture line.

Periprosthetic femoral fractures are increasing in frequency and complexity. They are technically demanding to treat since they require the skills of trauma surgery as well as those of revision arthroplasty. ${ }^{1}$

They occur intra-operatively in about $1 \%$ of cemented $^{2,3}$ and in $3 \%$ to $18 \%$ of uncemented ${ }^{4}$ primary hip arthroplasties and in $6.3 \%$ in cemented and $17.6 \%$ in uncemented revision procedures. $^{5-10}$

There have been several attempts at classifying periprosthetic femoral fractures. The Vancouver classification ${ }^{11}$ has been evaluated for its reliability and validity and represents the most comprehensive system since it considers the configuration of the fracture, the stability of the implant and the quality of bone stock (Table I). Fractures around the stem and the tip of the femoral prosthesis are the most common (type B). Non-operative treatment has little place since it has a high incidence of mal- and nonunion and requires prolonged immobilisation which is undesirable in older patients. ${ }^{12,13}$ When the stem is well fixed and the quality of the surrounding bone is good (type B1), open reduction and internal fixation with or without cortical onlay strut allografts may be used. 5,14-17

Fractures around loose implants with surrounding bone of relatively good quality (type
B2) necessitate revision of the stem. ${ }^{18,19}$ Cemented long stems are best reserved for older patients with simple fracture patterns in whom extrusion of the cement can be minimised to avoid nonunion. ${ }^{20}$ Long cementless stems, usually fixed distally, with porous coating, provide both stability of the implant and fixation of the fracture. ${ }^{21,22}$ Distal fixation can also be achieved with grooved or slotted long stems if the diaphyseal bone is intact. ${ }^{23,24}$

When the diaphyseal bone is very comminuted or osteolytic, there is little potential for press-fit distal fixation (type B3) and there are very few reconstructive options.

An approach to this problem has been to encourage osseointegration with extensive porous-coated or cone-tipped stems. The short- to medium-term results appear to be satisfactory although concerns remain about proximal stress shielding and loss of bone stock. $^{21,22}$ By contrast, proximally porouscoated stems osseointegrate poorly even if they treat the fracture successfully. ${ }^{9,25}$

In younger patients ${ }^{13}$ proximal femoral replacement, with a step-cut osteotomy at the bone-allograft junction, allows retention of the patient's own femur as a bivalved vascularised autograft around the bone-allograft junction. $^{26}$ Head, Emerson and Malinin ${ }^{27}$ in a 
Table I. Vancouver classification for periprosthetic femoral fractures

\begin{tabular}{lll}
\hline Fracture type & Anatomical location & Subtypes \\
\hline A & Proximal to the stem & AG (greater trochanter) \\
& Around the stem and cement mantle & B1; stable stem and adequate bone stock \\
B & B2; unstable stem and adequate bone stock \\
& & B3; unstable stem and inadequate bone stock \\
C & Well below the stem & \\
\hline
\end{tabular}

series of 262 procedures had a rate of success of $85 \%$ with this technique. Finally, massive modular prosthetic replacement of the proximal femur generally used in limb-salvage operations for neoplastic disease, is recommended in the elderly with limited life expectancy. ${ }^{18}$

We present the clinical results of an alternative technique of femoral reconstruction in which fresh frozen cancellous allograft bone chips were impacted into the femoral canal to provide a so-called neo-endosteum for components inserted with cement in type-B2 and type-B3 periprosthetic fractures. Impaction cancellous allografting was initially used for acetabular reconstruction of protrusio acetabuli, ${ }^{28}$ and then adopted for femoral reconstruction without cement in 1985 and eventually used with the cemented polished tapered Exeter prosthesis in $1993 .{ }^{29}$ The technique has since been extensively reported by several groups along with its biological and biomechanical aspects. ${ }^{30-49}$

\section{Patients and Methods}

Between 1985 and 2000, we treated 144 periprosthetic femoral fractures. They were classified according to the Vancourver classification system (Table I). ${ }^{11}$ There were 126 type B, five type A and 13 type C. Of the 126 type-B fractures, 106 were Vancouver subtypes B2 and B3, and 20 B1. Type-A, type-C and subtype-B1 fractures were exclud- ed from the study since they did not require revision with bone augmentation. Patients with simultaneous peri-prosthetic acetabular fractures and fractures of the distal femur above a total knee replacement were also excluded.

A retrospective review of the notes of these patients allowed the clinical details, surgical treatment with particular reference to the impaction grafting technique and follow-up to be recorded. We also reviewed serial radiographs (anteroposterior and lateral) noting the length of the prosthesis pre- and post-operatively, the type of stem used, the method of fixation and the rate of union. The femoral diameter was measured in the unaffected part of the ipsilateral femur or in the contralateral femur when comminution or osteolysis prevented this. The revision stems were subsequently classified as 'long' if they bypassed the most distal fracture line by the diameter of the ipsilateral diaphysis or more, and 'short' if they did not.

The fractures occurred after low-energy injuries, usually domestic or the result of a fall in most cases. The review was conducted simultaneously by two observers (ET, AAN) who took no part in the management of these fractures at any stage.

Of the patients with type- $\mathrm{B} 2$ and type-B3 fractures 32 were men and 74 women with a mean age of 68 years ( 39 to 91 ). Eighty-nine were treated by long-stem and 17 by

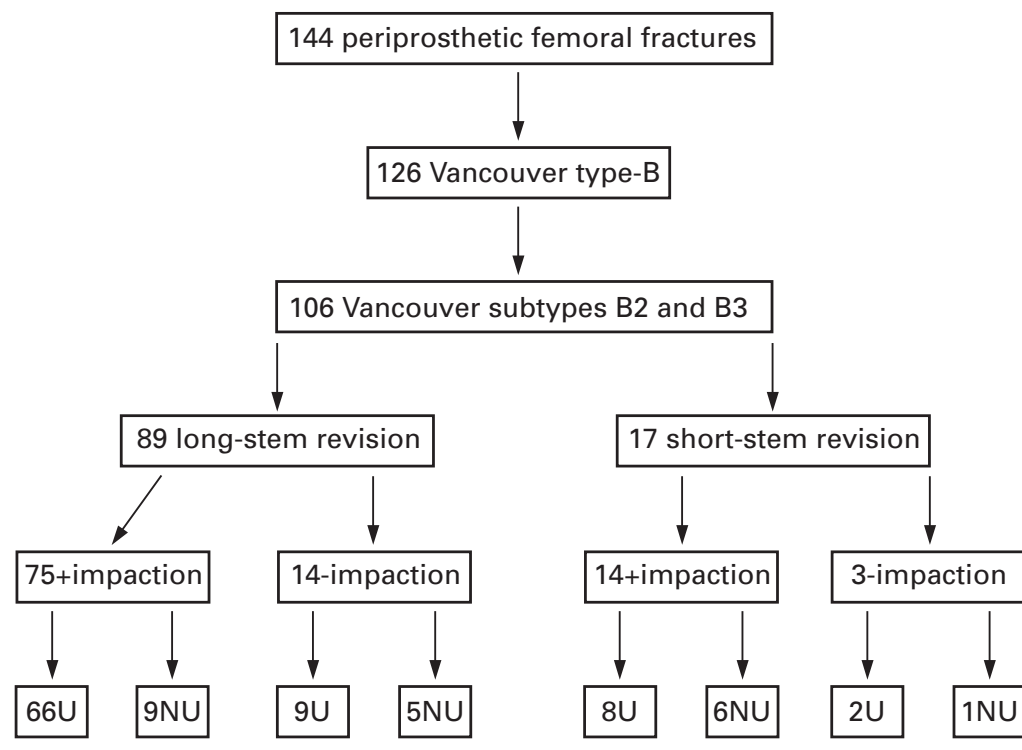

Fig. 1

Flow diagram showing the distribution of the 106 cases of peri-prosthetic femoral fracture $(U$, united fracture; $\mathrm{NU}$, not united fracture; + impaction, with impaction grafting; - impaction, without impaction grafting).

VOL. 86-B, No. 8, NOVEMBER 2004 
short-stem revision. In 89 patients cemented stems (75 long and 14 short) and impaction grafting were used to treat the inadequate bone stock. In the other 17 patients, cemented revision stems (14 long and 3 short) without impaction grafting were used (Fig. 1).

Operative technique

Approach and reduction of fracture. A long posterolateral incision either incorporating, or by excising the previous scar was made. The hip was aspirated before incising the capsule and histological examination was routinely requested. If there were $\geq 10^{5}$ neutrophils per high power field (HPF), clinical suspicion of infection with $10^{4}$ to $10^{5}$ organisms per HPF, or identification of organisms, the procedure was abandoned in favour of a two-stage revision. The site of the fracture provided access for removal of the prosthesis and cement. The fracture was then reduced over a phantom femoral stem with the fragments held by cerclage monofilament wires, cables, strut grafts or plates. An extended trochanteric osteotomy was occasionally used to improve access. No infected periprosthetic fractures were found in our series.

Preparation of the graft. Fresh-frozen femoral heads screened for transmissable disease during donation and after six months were used. Compatability was not assessed. Initially, we used the Aesculap bone mill (Aesculap, Sheffield, UK) to morsellise the femoral heads but soon changed to the Tracer bone mill (Tracer Designs, Santa Paula, California), which produced larger bone chips. Recently, we have used the Noviomagus bone mill (A-one Medical BV, Nijmegen, The Netherlands) which becomes blunt less easily than the previous devices. We did not use large nibbler-made chips in the proximal femur until about five years ago. Before this, all the chips were milled and of uniform size.

Currently, two sizes of bone chips are prepared; those of 2 to $4 \mathrm{~mm}$ are used for the distal canal and those $>5 \mathrm{~mm}$ and up to $10 \mathrm{~mm}$ for the proximal, more capacious, femur. Pure cancellous or corticocancellous chips are ideal; thick cortical fragments from the calcar donor are removed.

Preparation of the femur. After removal of the prosthesis and cement and reduction of the fracture, defects in the femur were reconstructed before impaction grafting with Mesh (Stryker-Howmedica Osteonics, Caen, France) and monofilament cerclage wires. The canal was occluded distally using a threaded plug attached to a guidewire. If the required position lay beyond the isthmus, it was skewered with a percutaneous wire or seated on an earlier placed cement plug.

Impaction of the graft. In our series after packing with distal impactors, the long stem was hammered in to keep the canal open. This was subsequently removed and the canal packed again, before the same process was repeated. Long stem impaction instruments (Stryker-Howmedica) have, however, become available recently.

Distal and proximal allograft bone chip packing was then performed over a central guide wire using the appropriate sized distal impactors and proximal phantom stems. The distal impaction was continued until the level of the chips was up to the level of the tip of the phantom impactor. The canal was then filled and repetitively impacted with the slaphammer attached to the phantom impactor until the neoendosteum was formed. Antibiotic Simplex bone cement (Howmedica, Auckland, New Zealand) was then pressurised into the neo-endosteum. Cemented Exeter (StrykerHowmedica-Osteonics, Caen, France) polished collarless tapered stems were used in all cases. A wingless Exeter stem centraliser was fitted to the end of the stems before insertion.

Post-operative management. Post-operatively, the patients were instructed to walk with toe-touch weight-bearing for three months. Progressive weight-bearing was then encouraged. All the patients were allowed to bear weight fully after a maximum of six months from the date of fixation of the fracture. Currently, however, we advise restricted weight-bearing for only six weeks if the bone stock is not severely compromised before impaction revision, and for three months if it is.

Assessment. The patients were followed up clinically and radiologically for $6,12,26$ and 52 weeks post-operatively. The fracture was considered to be united if it met radiological and clinical criteria after 52 weeks.

Radiological union was defined as cortical continuity on both the anteroposterior and the lateral radiographs with external formation of callus. External callus could not always be seen circumferentially because of wires, cables, meshes, plates and occasionally strut grafts. Clinical union was defined as pain-free full weight-bearing or with occasional pain not compromising daily activities or walking, with or without aids. The Harris hip score (HHS) was recorded after 52 weeks.

Statistical analysis. This was carried out using STATA software (version 7.0, STATA Corp LP, College Station, Texas). Proportions were analysed by using logistic regression. The outcome measure was union and the variables assessed were the length of the stem, the use of impaction grafting and their combination. The odds ratios and their $95 \%$ confidence intervals $(\mathrm{CI})$ and $\mathrm{p}$ values were calculated.

\section{Results}

The flow diagram (Fig. 1) shows the overall breakdown of the management and outcome of the fractures of which 85 eventually united $(80.2 \%)$ leaving 21 nonunions (19.8\%) in all groups. More specifically, 75 of $89(84.3 \%)$ fractures treated with long stems united compared with only ten of $17(58.82 \%)$ treated with short stems. Furthermore, 66 of $75(88 \%)$ of fractures treated by impaction grafting with long-stem prostheses united compared with only eight of 14 $(57.1 \%)$ treated by impaction grafting and short-stem prosthesis.

Table II shows the rates of union in each subgroup and the odds of union for those with a long versus a short stem, and those using impaction grafting versus those without. Fractures treated by a long stem were almost four times 
Table II. Association between union, length of stem, impaction grafting and the relationship between the stem length and impaction grafting

\begin{tabular}{|c|c|c|c|c|}
\hline & \multicolumn{4}{|l|}{ Union } \\
\hline & \multirow{2}{*}{$\begin{array}{l}\text { Yes } \\
\text { Number (\%) }\end{array}$} & \multirow{2}{*}{$\frac{\text { No }}{\text { Number (\%) }}$} & \multirow{2}{*}{$\begin{array}{l}\text { Odds ratio } \\
(95 \% \mathrm{Cl})\end{array}$} & \multirow[b]{2}{*}{ p value } \\
\hline & & & & \\
\hline \multicolumn{5}{|l|}{ Length of stem } \\
\hline Long & 75 (88) & $14(66.6)$ & $3.75(1.21$ to 11.6$)$ & 0.022 \\
\hline Short & $10(12)$ & 7 (33.3) & & \\
\hline Total & $85(100)$ & $21(100.0)$ & & \\
\hline \multicolumn{5}{|l|}{ Impaction grafting } \\
\hline With & $74(87)$ & $15(71)$ & $2.69(0.86$ to 8.45$)$ & 0.090 \\
\hline Without & $11(13)$ & $6(29)$ & & \\
\hline Total & $85(100)$ & $21(100)$ & & \\
\hline \multicolumn{5}{|l|}{ Long stem } \\
\hline With impaction grafting & $66(88)$ & $9(64)$ & $4.07(1.10$ to 15.0$)$ & 0.035 \\
\hline Without impaction grafting & $9(12)$ & $5(36)$ & & \\
\hline Total & $75(100)$ & $14(100)$ & & \\
\hline Long stem with impaction grafting & $66(89)$ & $9(60)$ & 5.5 (1.54 to 19.6$)$ & 0.009 \\
\hline Short stem with impaction grafting & $8(11)$ & $6(40)$ & & \\
\hline Total & $74(100)$ & $15(100)$ & & \\
\hline
\end{tabular}

more likely to unite than those treated by a short stem (odds ratio $=3.75 ; 95 \%$ CI 1.21 to $11.6 ; \mathrm{p}=0.022$; Fig. 2 ). Fractures treated by a cemented long stem with impaction grafting were significantly more likely to unite than those treated without (odds ratio $=4.07 ; 95 \%$ CI 1.10 to $15.0 ; \mathrm{p}$
$=0.035$; Figs 3 and 4). Fractures with impaction grafting were five times more likely to unite if a long rather than short cemented stem was used (odds ratio $=5.5 ; 95 \% \mathrm{CI}$ 1.54 to $19.6 ; \mathrm{p}=0.009$; Fig. 5). There was a trend towards fractures treated with impaction grafting uniting more

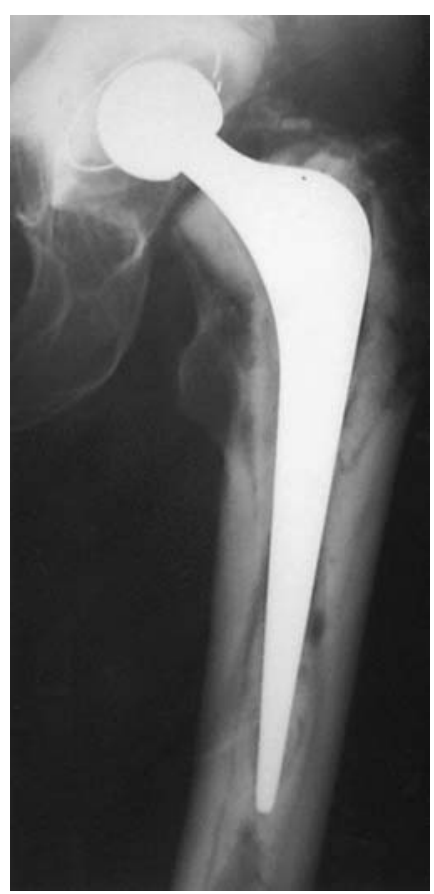

Fig. $2 a$

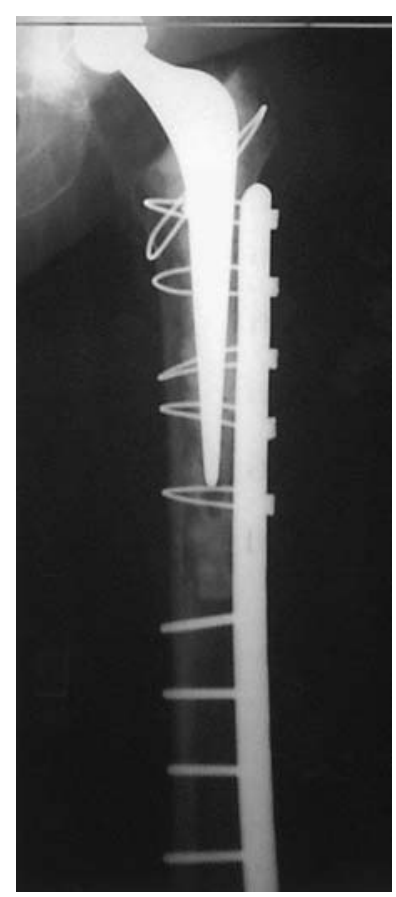

Fig. $2 b$

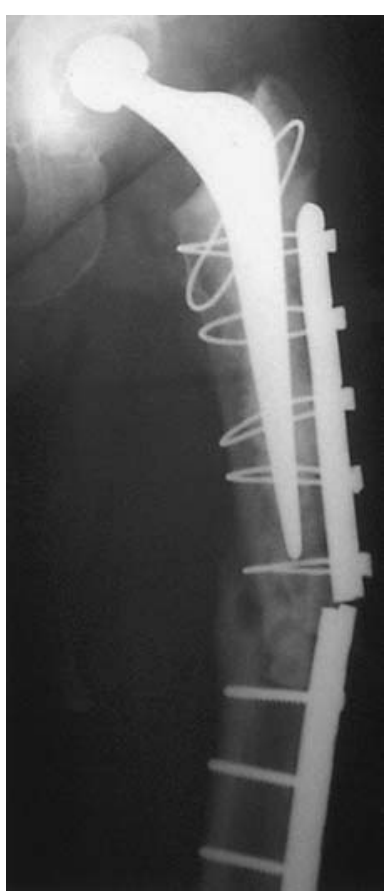

Fig. 2c

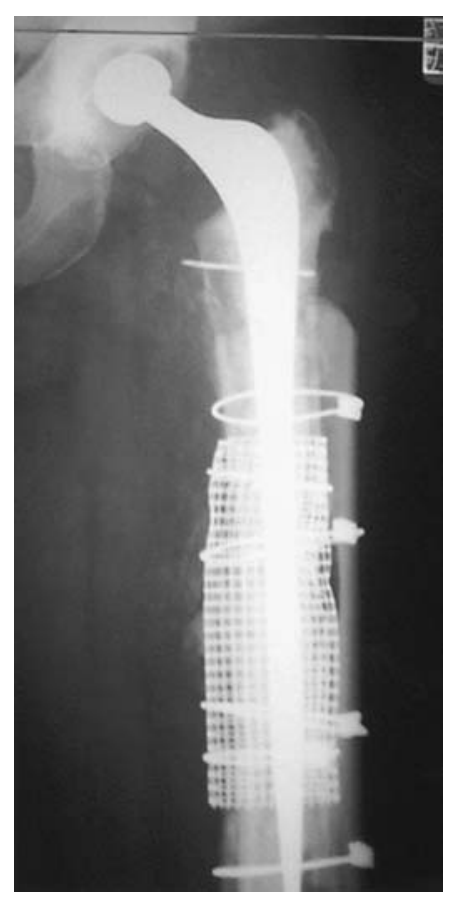

Fig. 2d

Figure $2 \mathrm{a}$ - Radiograph showing an unstable stem and a comminuted undisplaced fracture. Removal of the cement reduced the bone stock to the extent that impaction grafting was necessary to treat the deficient bone. Figure $2 b$ - Radiograph showing impaction grafting revision using a short stem. Reduction was maintained using a D/M plate. Figure 2c-Radiograph showing nonunion with fracture of the D/M plate. Figure $2 \mathrm{~d}-\mathrm{Radiog}$ raph showing impaction grafting revision to a long stem. Additional fixation was achieved using two strut grafts to the anterior and lateral femoral surfaces. 


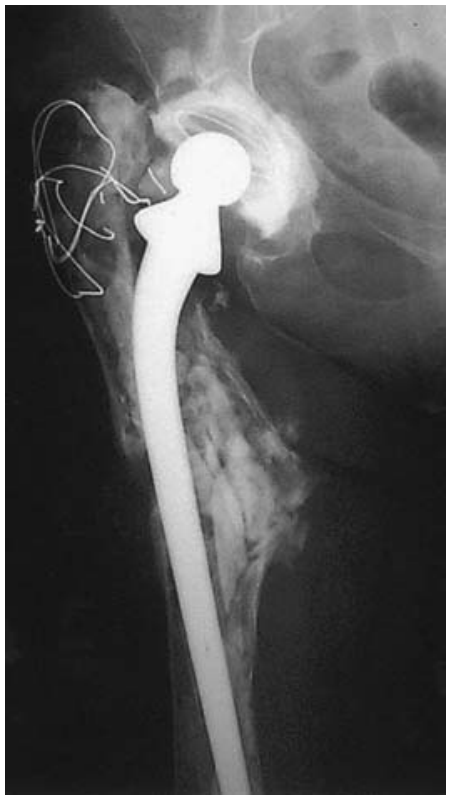

Fig. 3

Radiograph showing a long-standing nonunion after revision using a cemented long stem for a peri-prosthetic femoral fracture of the midshaft.

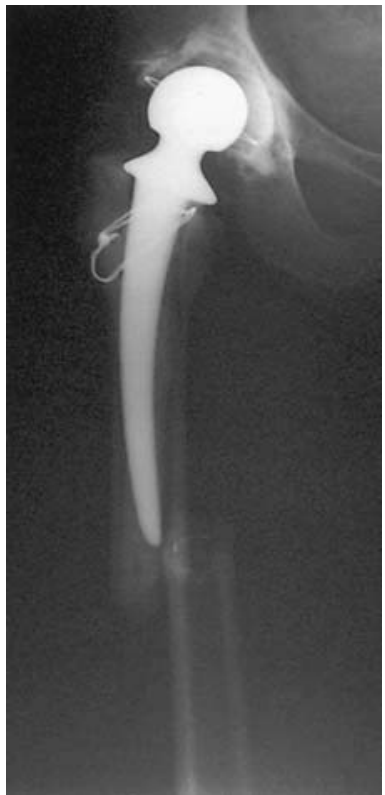

Fig. $4 \mathrm{a}$

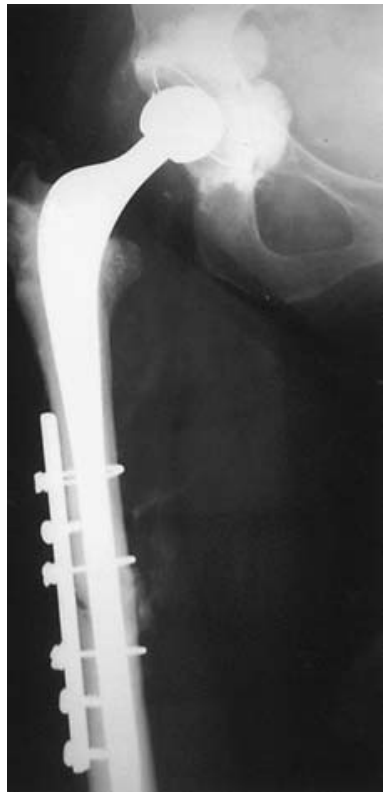

Fig. $4 \mathrm{~b}$
Radiographs showing a) a peri-prosthetic femoral fracture (Vancouver type-B2) and b) revision using a long stem without impaction grafting. There was a successful application of a DCP plate and formation of callus on the medial aspect of the femur. There is delayed union of the lateral aspect of the fractured femur under the plate.

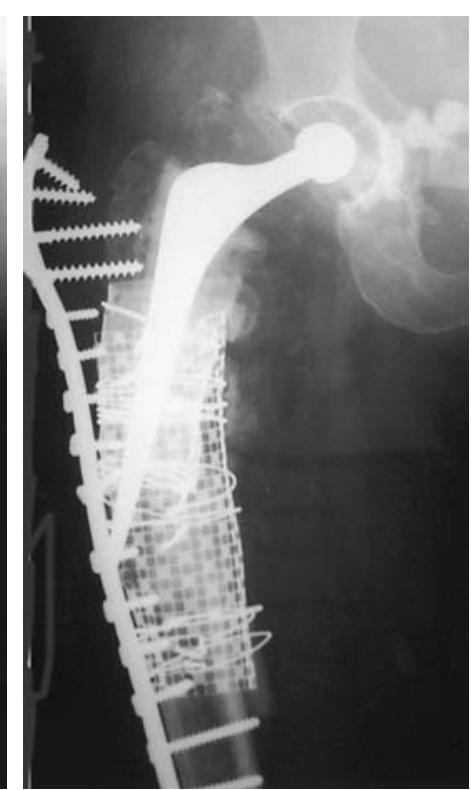

Fig. 5c

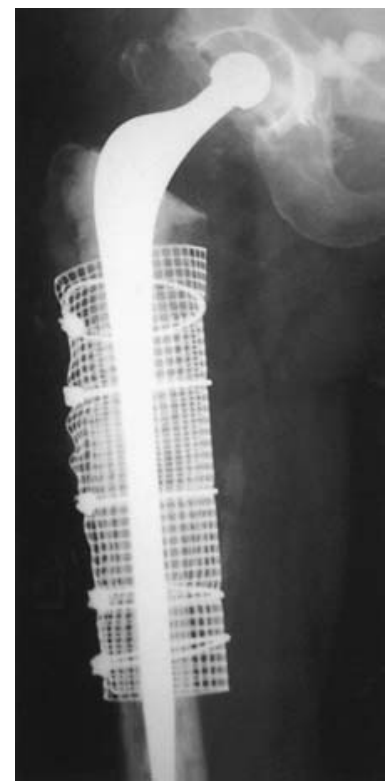

Fig. 5d
Fig. 5a
Fig. 5b

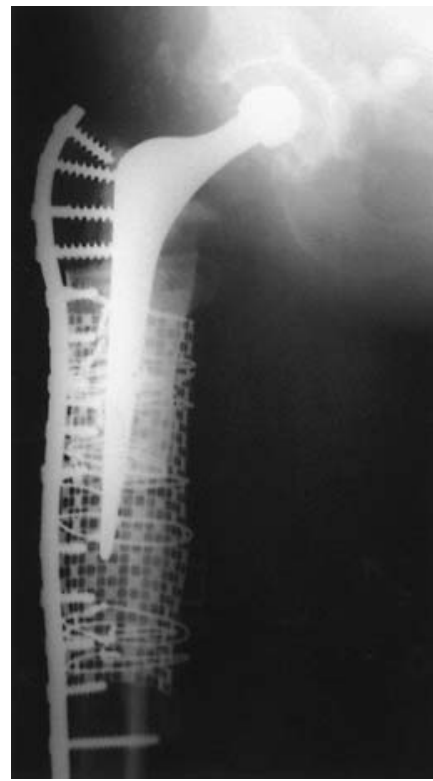

Radiographs showing a) a Vancouver type-B3 fracture, b) short-stem revision with impaction grafting and a long DCP plate, c) nonunion and pull-out of the plate and d) a long-stem revision with impaction grafting, mesh and D/M cables.

readily (odds ratio $=2.69 ; 95 \%$ CI 0.86 to $8.45 ; \mathrm{p}=0.090$ Fig. 6).

Only three patients were treated by a cemented shortstem revision without impaction grafting and one failed to unite (Figs $2 \mathrm{a}$ and $2 \mathrm{~b}$ ).
Supplementary fixation with strut grafts, dynamic compression plates (DCP) and Dall/Miles plates (D/M) was used. Table III shows the use of strut grafts in each group. One or two strut grafts was used to the anterior and/or lateral aspect of the femur. In one of the 11 patients in whom 


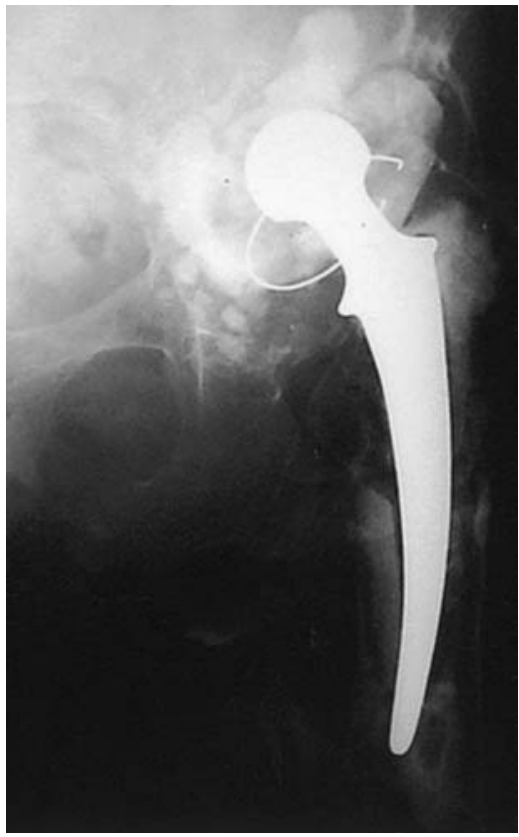

Fig. $6 a$

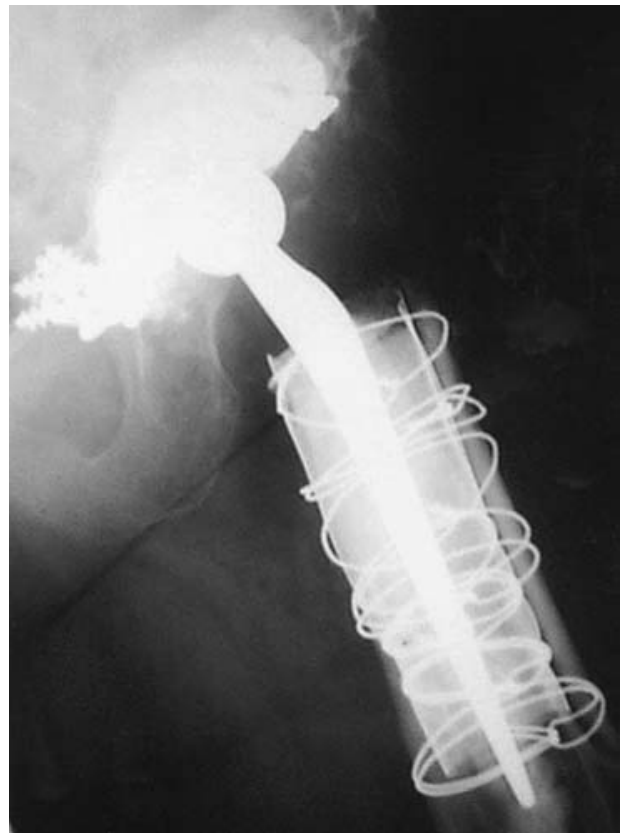

Fig. $6 \mathrm{~b}$

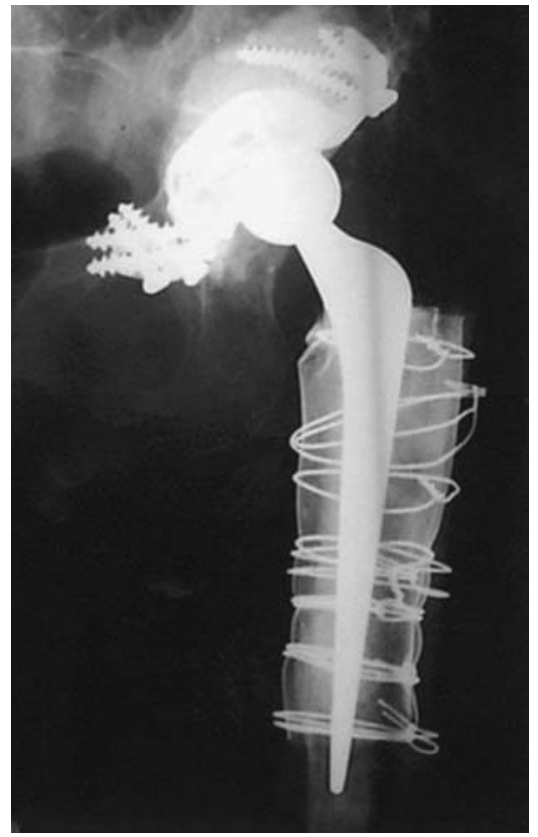

Fig. 6c

Radiographs showing a) an intra-operative periprosthetic femoral fracture during revision of a left total hip replacement with very poor bone quality and a loose prosthesis, b) revision to a short stem and impaction grafting with the addition of two strut grafts and c) a stable prosthesis with incorporation of the struts and impacted allograft to the host bone.

Table III. Details of the supplementary fixation with strut grafts

\begin{tabular}{llllc}
\hline & Short + impaction* & Short - impactiont & Long + impaction & Long - impaction \\
\hline With strut & 1 & 1 & 9 & 0 \\
Without strut & 13 & 2 & 66 & 14 \\
Total & 14 & 3 & 75 & 14 \\
\hline * + impaction, with impaction grafting & & \\
$\dagger$ & - impaction, without impaction grafting
\end{tabular}

Table IV. Details of struts used and healing

\begin{tabular}{llll}
\hline & \multicolumn{2}{l}{ Number of struts } \\
\cline { 2 - 4 } & $\mathbf{1 \dagger}$ & $\mathbf{2 \dagger}$ & Total \\
\hline Short-impaction+strut* & $1(\mathrm{NU})$ & 0 & 1 \\
Long+impaction+strut* & $6(\mathrm{U})$ & $3(\mathrm{U})$ & 9 \\
Short+impaction+strut* & 0 & $1(\mathrm{U})$ & 1 \\
\hline
\end{tabular}

* + impaction, with impaction grafting; - impaction, without impaction grafting

$\dagger U$, united fracture; NU, not united fracture

additional fixation with strut grafts was used union did not occur. In this case a short stem without impaction grafting and one strut were used (Table IV).

In two of 12 patients in whom a DCP had been used, the fracture failed to unite (Fig. 5c). Both had a short stem, one with and one without impaction grafting. There was nonunion also in one of the nine patients in whom a $\mathrm{D} / \mathrm{M}$ plate had been used with a short stem and impaction grafting (Fig. 2; Table V).

The mean healing time for all united fractures was 7.44 months (3 to 12$)$. The HHS was recorded in $66(62.26 \%)$ of the 106 fractures after 52 weeks. All united with a mean HHS of 81 (55 to 91). Twenty-one (19.8\%) fractures failed to unite. Fourteen had long stems, nine with and five without impaction grafting. Seven had short stems, six with and one without impaction grafting. Overall, there werefour $(3.7 \%)$ infections, two with a long stem and impaction grafting and two with a short stem and impaction grafting (Table VI).

\section{Discussion}

In the surgical treatment of periprosthetic femoral fractures, configuration of the fracture, the stability of the stem, and the underlying bone stock should be considered. ${ }^{1,7}$

Fractures around unstable stems with poor quality surrounding bone require revision of the stem and massive replacement or reconstruction of the proximal femur. The latter is often achieved either by using massive structural allografts or extra-medullary cortical allograft plates. Proximal femoral replacement with fresh frozen allograft has been successfully used. The massive allografts seem to unite with the host bone at the step-cut junction and to survive in 
Table V. Supplementary fixation with DCP or D/M plates and healing

\begin{tabular}{lllllr}
\hline & Short + impaction* & Short - impaction* & Long + impaction* & Long - impaction* & Total \\
\hline $\mathrm{DCP}$ & $4(\mathrm{U}=2, \mathrm{NU}=2) \dagger$ & 0 & $7(\mathrm{U}=7) \dagger$ & $1(\mathrm{U}=1) \dagger$ & 12 \\
$\mathrm{D} / \mathrm{M}$ & $3(\mathrm{U}=2, \mathrm{NU}=1) \dagger$ & 0 & $6(\mathrm{U}=6) \dagger$ & 0 & 9 \\
Total & 7 & 0 & 13 & 1 & 21 \\
\hline
\end{tabular}

* + impaction, with impaction grafting; - impaction, without impaction grafting

$\dagger U$, united fracture; NU, not united fracture

Table VI. Details of complications by length and type of grafting

\begin{tabular}{|c|c|c|c|c|c|}
\hline Complication & Short + impaction* & Short - impaction* & Long + impaction* & Long - impaction* & Total \\
\hline Infection & 2 & 0 & 2 & 0 & 4 \\
\hline NUt & 4 & 1 & 7 & 5 & 17 \\
\hline Total & 6 & 1 & 9 & 5 & 21 \\
\hline
\end{tabular}

* + impaction, with impaction grafting; - impaction, without impaction grafting

$\dagger \mathrm{NU}$, not united fracture

long-term follow-ups. ${ }^{12,13,26,27}$ Extra-medullary enhancement of the proximal femoral host bone and its mechanical strengthening can be achieved by placing cortical allograft strut grafts around the deficient bone. The biological and biomechanical status of strut grafts, their immunogenicity, and the experimental and clinical biocompatibility and efficacy of this technique, has been extensively studied and the use of the cortical strut grafts is well established in the literature. ${ }^{32,50,51}$

Impaction grafting has been recently introduced as an intra-medullary grafting technique for the reconstruction of the proximal femur in hip revision procedures. It is based on earlier experience of a similar technique employed in acetabular reconstruction. ${ }^{28}$ The technique was originally used in Exeter with a cementless prosthesis but soon after this, cement was used to achieve better primary stability. ${ }^{29}$ Morsellised fresh frozen cancellous or corticocancellous allograft chips were impacted into the femoral canal to provide a so-called neo-endosteum for a prosthesis to be inserted with cement. ${ }^{29}$ Early results of the impaction grafting revision technique for the femur have been encouraging $29,33,34$ but some series have demonstrated complications such as intra- and post-operative fractures and subsidence. ${ }^{35-38}$

In addition, the biological and biomechanical efficacy of the impaction grafting technique has been studied. ${ }^{31,39-49}$ The ability of the cancellous bone allograft to survive and remodel through re-vascularisation is well understood. Roffman et $\mathrm{al}^{40}$ have shown that bone grafts, even when covered with methylmethacrylate bone cement, still retain their viability as well as their osteogenic potential. Ling et $\mathrm{al}^{42}$ have found that impacted bone had been organised in three zones with the outer zone largely replaced by viable cortical bone, and the same histological findings have been confirmed by other investigators recently. ${ }^{34,49}$

The mechanical strength of the bone chips following impaction has also been studied and improvement has been achieved in terms of graft size, compaction forces and cementing technique. ${ }^{31,40-48}$ The biological potential of the technique is self-evident ${ }^{34,40,42,44,49}$ and the plasticity of the impacted bone in reconstructing the deficient bone allows the surgeon to use conventional cemented prostheses. The impaction grafting technique was suggested as the treatment of choice for patients with very severe bone loss by the Leopold and Rosenberg algorithm for femoral reconstruction. ${ }^{30}$ More specifically, when the canal diameter is over 20 $\mathrm{mm}$, and less than $4 \mathrm{~cm}$ of intact diaphysis is available for press-fit revision, an extensively coated stem is not suitable for distal fixation. This description reflects to a large extent our clinical experience from the majority of the B3 periprosthetic femoral fractures included in this study.

The use of impaction grafting for the treatment of typeB2 and type-B3 periprosthetic femoral fractures has not been previously published to the best of our knowledge. In our study, we have reviewed the treatment of periprosthetic femoral fractures using impaction grafting over a period of 15 years. The technique was augmented by the use of strut grafts, ${ }^{32,50,51}$ plates and cerclage wires or cables to achieve and maintain the reduction of the fracture during graft impaction and implantation of a cemented stem.

In the original impaction grafting technique used until 1996 , the cemented stem rarely bypassed the distal fracture and bone chips 2 to $4 \mathrm{~mm}$ in size were used. This construct failed in terms of healing of the fracture with a rate of nonunion of $43 \%$. Based on these findings and recent laboratory work ${ }^{43,45-48}$ we changed our practice and since 1996 , have used chips of a different size for distal and proximal impaction with long cemented stems.

The newer technique was better in terms of healing with a rate of union of $88 \%$ within a mean of 7.44 months.

In fractures around an unstable stem with surrounding bone of poor quality, the healing process is impaired by two major factors, the inadequate host bone and the relative stability of the construct after reduction and fixation.

It follows that the biological and biomechanical solution to the effective treatment of these fractures lies in the augmentation of the host bone and the stabilisation of the fracture to allow healing. Proximal allograft femoral 
replacement or strut grafting is successful, but the vascular invasion of the thick cortical allograft is slow and incomplete. . $^{32,52,53}$

By contrast, cancellous allograft impaction grafting is a more biological solution since it reconstructs the bone from inside out, and allows easy vascular invasion and remodelling. ${ }^{31,54}$ In addition, impacted allograft prevents the extrusion of cement and its interposition between fragments, and reduces the rate of nonunion.

Plates assisted reduction of the fracture stability and healing. They contain cortical defects and allow impaction of bone chips. With the numbers available in this retrospective study, it is difficult to draw valid conclusions about the efficacy of each plate but all fractures treated using a long stem with impaction grafting and strut grafts healed whereas only one of the two fractures in which a short stem and impaction grafting were used with a struft graft united.

Our experience in treating type-B2 and type-B3 periprosthetic femoral fractures suggests that the stability of the impaction grafting construct should rely on both extra- and intra-medullary fixation. External stability is mainly achieved by extra-medullary fixation devices, such as biological strut grafts or non-biological plates and cables. Internal stability can be achieved and maintained by a stem which bypasses the most distal fracture line.

In impaction grafting, a long-stem component is necessary to bypass the most distal fracture line. Short stems fail because of a lack of stability. At least one year is required for impacted allograft to incorporate and remodel. ${ }^{30,31,54}$ In the short term, impaction grafting offers only relative stability and is usually inadequate for bone healing. In the long term, bone remodels around the stem and provides further stability. We suggest that impaction grafting can be used effectively to augment the bone stock in type-B2 and typeB3 periprosthetic femoral fractures, but cannot be relied on its own for short-term stability. It should always be supported by a long stem, bypassing the most distal fracture line.

Type-B2 and type-B3 femoral periprosthetic fractures represent one of the most difficult reconstructive challenges for the revision hip surgeons. Impaction grafting offers a useful and successful solution.

Mr Eleftherios Tsiridis was supported by the Alexander S. Onassis Public Benefit Foundation, Greece.

No benefits in any form have been received or will be received from a com mercial party related directly or indirectly to the subject of this article.

\section{References}

1. Tsiridis E, Haddad GS, Gie GA. The management of periprosthetic femoral fractures around hip replacements. Injury 2003;34:95-105.

2. Garcia-Cimbrelo E, Munuera L, Gil-Garay E. Femoral shaft fractures after cemented total hip arthroplasty. Int Orthop 1992;16:97-100.

3. Lowenhielm G, Hansson LI, Kärrholm J. Fractures of the lower extremity after total hip replacement. Arch Orthop Trauma Surg 1989;108:141-3.

4. Mont MA, Maar DC, Krackow KA, Hungerford DS. Hoop-stress fractures of the proximal femur during hip arthroplasty: management and results in 19 cases. J Bone Joint Surg [Br] 1992;74-B:257-60.

5. Stuchin SA. Femoral shaft fracture in porous and press-fit total hip arthroplasty. Orthop Rev 1990;19:153-9
6. Christensen CM, Seger BM, Schultz RB. Management of intra-operative femur fractures associated with revision hip arthroplasty. Clin Orthop 1989;248:177-80.

7. Garbuz DS, Masri BA, Duncan CP. Periprosthetic fractures of the femur principles of prevention and management. Instr Course Lect 1998;47:237-42.

8. Morrey BF, Kavanagh BF. Complications with revision of the femoral component of total hip arthroplasty: comparison between cemented and uncemented techniques. J Arthroplasty 1992;7:71-9.

9. Kavanagh BF. Femoral fracture associated with total hip arthroplasty. Orthop Clin North Am 1992;23:249-57.

10. Beals RK, Tower SS. Periprosthetic fractures of the femur: an analysis of $93 \mathrm{frac}$ tures. Clin Orthop 1996;327:238-46.

11. Brady OH, Garbuz DS, Masri BA, Duncan CP. Classification of the hip. Orthop Clin North Am 1999;30:215-20.

12. Berry DJ. Management of periprosthetic fractures of the hip. J Arthroplasty2002;17 $11-3$

13. Bethea JS 3rd, DeAndrade JR, Fleming LL, Lindenbaum SD, Welch RB. Proximal femoral fractures following total hip arthroplasty. Clin Orthop 1982;170:95-106.

14. Montijo H, Ebert FR, Lennox DA. Treatment of proximal femur fractures associated with total hip arthroplasty. J Arthroplasty 1989;4:115-23

15. Mont MA, Maar DC. Fractures of the ipsilateral femur after hip arthroplasty: a statistical analysis of outcome based on 487 patients. J Arthroplasty 1994;9:511-19.

16. Wang GJ, Miller T0, Stamp WG. Femoral fractures following hip arthroplasty: brief note on treatment. J Bone Joint Surg [Am] 1985;67-A:956-8.

17. Head WC, Malinin TI, Mallory TH, Emerson RH Jr. Onlay cortical allografting for the femur. Orthop Clin North Am 1998;29:307-12.

18. Duncan CP, Masri BA. Fractures of the femur after hip replacement. Instr Course Lect 1995;44:293-304.

19. Lewallen DG, Berry DJ. Periprosthetic fractures of the femur after total hip arthro plasty: treatment and results to date. Instr Course Lect 1998;47:243-9.

20. Cook PH, Newman JH. Fractures of the femur in relation to cemented hip prostheses. J Bone Joint Surg [Br] 1988;70-B:386-9.

21. Macdonald SJ, Paprosky WG, Jablonsky WS, Magnus RG. Periprosthetic femoral fractures treated with a long-stem cementless component. J Arthroplasty 2001 16:379-83.

22. Moran MC. Treatment of periprosthetic fractures around total hip arthroplasty with an extensively coated femoral component. J Arthroplasty 1996;11:981-8.

23. Incavo SJ, Beard DM, Pupparo F, Ries M, Wiedel J. One-stage revision of periprosthetic fractures around loose cemented total hip arthroplasty. Am J Orthop 1998;27:35-41.

24. Kolstad K. Revision TKR after periprosthetic femoral fractures: an analysis of 23 cases. Acta Orthop Scand 1994;65:505-8.

25. Malkani AL, Lewallen DG, Cabanela ME, Wallrichs SL. Femoral component revision using an uncemented, proximally coated, long-stem prosthesis. J Arthroplasty 1996;11:411-18

26. Wong P. Gross AE. The use of structural allograft for treating periprosthetic fractures about the hip and the knee. Orthop Clin North Am 1999;30:259-64.

27. Head WC, Emerson RH Jr, Malinin TI. Structural bone grafting for femoral reconstruction. Clin Orthop 1999;369:223-9.

28. Slooff TJJH, Huiskes R, van Horn J, Lemmens AJ. Bone grafting in total hip replacement for acetabular protrusion. Acta Orthop Scand 1984;55:593-6.

29. Gie GA, Linder L, Ling RSM, et al. Impacted cancellous allografts and cement for revision total hip arthroplasty. J Bone Joint Surg [Br] 1993;75-B:14-21.

30. Leopold SS, Rosenberg AG. Current status of impaction allografting for revision of a femoral component. Instr Course Lect 2000;49:111-18.

31. Callaghan JJ, Heiner AD, Brown TD. The basic science of impaction allografting in revision hip surgery. Instr Course Lect 2000;49:103-10.

32. Emerson RH Jr. Basic science of onlay allografts: a review. Instr Course Lect 2000; 49:97-102.

33. Elting JJ, Mikhail WE, Zicat BA, et al. Preliminary report of impaction grafting for exchange femoral arthroplasty. Clin Orthop 1995;319:159-67.

34. Nelissen RGHH, Bauer TW, Weidenhielm LRA, LeGolvan DP, Mikhail WEM Revision hip arthroplasty with the use of cement and impaction grafting: histological analysis of four cases. J Bone Joint Surg [Am]1995;77-A:412-22.

35. Eldridge JD, Smith EJ, Hubble MJ, Whitehouse SL, Learmouth ID. Massive early subsidence following femoral impaction grafting. J Arthroplasty 1997;12 $535-40$

36. Masterson EL, Masri BA, Duncan CP. The cement mantle in the Exeter impaction grafting technique: a cause of concern. J Arthroplasty 1997;12:759-64.

37. Meding JB, Ritter MA, Keating EM, Faris PM. Impaction bone-grafting before insertion of a femoral stem with cement in revision total hip arthroplasty: a minimum 2-year follow-up study. J Bone Joint Surg [Am]1997;79-A:1834-41. 
38. Pekkarinen J, Alho A, Lepisto J, et al. Impaction bone grafting in revision hip surgery: a high incidence of complications. J Bone Joint Surg [Br] 2000;82-B: 103-7.

39. Berzins A, Sumner DR, Wasielewski RC, Galante J0. Impacted particulate allograft for femoral revision total hip arthroplasty: in vitro mechanical stability and effects of cement pressurization. J Arthroplasty 1996;11:500-6.

40. Roffman M, Silbermann M, Mendes DG. Viability and osteogenicity of bone graft coated with methylmethacrylate cement. Acta Orthop Scand 1982;53:513-19.

41. Linder L. Cancellous impaction grafting in the human femur: histological and radiographic observations in 6 autopsy/femurs and 8 biopsies. Acta Orthop Scand 2000;71: 543-52.

42. Ling RSM, Timperley AJ, Linder L. Histology of cancellous impaction grafting in the femur. J Bone Joint Surg [Br] 1993;75-B:693-6.

43. Bavadekar A, Cornu O, Godts B, et al. Stiffness and compactness of morsellized grafts during impaction. Acta Orthop Scand 2001;72:470-6.

44. Weidenhielm LRA, Mikhail WEM, Wretenberg P, et al. Analysis of the retrieved hip after revision with impaction grafting. Acta Orthop Scand 2001;72:609-14.

45. Hostner J, Hultmark P, Karrholm J, Malchau H, Tveit M. Impaction technique and graft treatment in revision of the femoral component: laboratory studies and clinical validation. J Arthroplasty 2001;16:76-82
46. Brewster NT, Gillespie WJ, Howie CR, et al. Mechanical considerations in impaction bone grafting. J Bone Joint Surg [Br] 1999;81-B:118-24

47. UlImark G, Nilsson $\mathbf{0}$. Impacted corticocancellous allografts: recoil and strength. J Arthroplasty 1999;14:1019-23.

48. Giesen EB, Lamerigts NM, Verdonschot N, et al. Mechanical characteristics of impacted morsellised bone grafts used in revision of total hip arthroplasty. J Bone Joint Surg [Br] 1999;81-B:1052-7.

49. Ullmark G, Obrant KJ. Histology of impacted bone-graft incorporation. J Arthroplasty 2002;17:150-7.

50. Haddad FS, Duncan CP, Berry DJ, et al. Periprosthetic femoral fractures around well-fixed implants: use of cortical onlay allografts with or without a plate. J Bone Joint Surg [Am] 2002;84-A:945-50.

51. Haddad FS, Duncan CP. Cortical onlay allograft struts in the treatment of periprosthetic femoral fractures. Instr Course Lect 2003;52:291-300.

52. Enneking WF, Mindell ER. Observations on massive retrieved human allografts. J Bone Joint Surg [Am] 1991;73-A:1123-42.

53. Huo MH, Friedlaender GE, Salvati EA. Bone graft and total hip arthroplasty: a review. J Arthroplasty 1992;7:109-20.

54. Slooff TJJ, Schreurs BW, Buma P, Gardeniers JWM. Impaction morsellized allografting and cement. Instr Course Lect 1999;48:79-89. 